\title{
Basile, Teresa (2019). Infancias. La narrativa argentina de HIJOS. Villa María: Eduvim, 300 pp.
}

\author{
Cueto Rúa, Santiago \\ Basile, Teresa (2019). Infancias. La narrativa argentina de HIJOS. Villa María: Eduvim, 300 pp. \\ Aletheia, vol. 10, núm. 19, 2019 \\ Universidad Nacional de La Plata, Argentina \\ DOI: https://doi.org/10.24215/18521606e037
}

Esta obra está bajo una Licencia Creative Commons Atribución-NoComercial-Compartirlgual 4.0 Internacional 
Reseñas, crónicas y notas de opinión

Basile, Teresa (2019). Infancias. La narrativa argentina de HIJOS. Villa María: Eduvim, 300 pp.

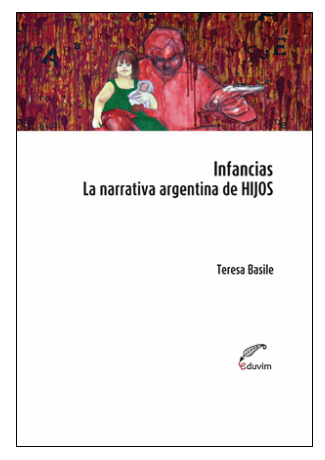

Infancias es un libro escrito por Teresa Basile, Doctora en Letras, docente e investigadora de la Facultad de Humanidades y Ciencias de la Educación de la UNLP. Basile ha producido a lo largo de su carrera una obra en la que indaga los vínculos entre literatura, política y memoria, focalizada en la experiencia de las dictaduras del Cono Sur. La autora elige en esta oportunidad abordar algunas de las consecuencias de la dictadura argentina, más específicamente la experiencia de la segunda generación de víctimas del terrorismo de Estado. Lo hace a partir de la obra ficcional de los HIJOS, aunque su recorte incluye también testimonios y otros discursos propios del campo cultural, como films o producciones fotográficas

Una de las claves del libro de Basile está en el plural de la palabra "Infancias" que le da título. A contramano de los estereotipos sociales que circulan en el espacio público, muchas veces guiados por la lógica de la unicidad, de lo monolítico, lo que Basile muestra es pura heterogeneidad. Su libro es, ante todo, un repaso por la multiplicidad de experiencias que implicó ser hijos e hijas de las víctimas del terrorismo de estado, y un análisis de cómo esa experiencia fue significada.

Esa multiplicidad de experiencias es enriquecida en el libro mediante un abordaje que potencia los recursos de la memoria. Las experiencias indagadas son construidas entonces no sólo a través del recuerdo, en tanto evocación de algo que está allí y se trae al presente, sino también a través de la ficción, lo que permite cruzar la memoria con lo documental, pero también con lo onírico y con la imaginación amplificadora de lo posible. En ese sentido, la autora se desentiende de la discusión acerca de la calidad literaria de las obras que aborda, puesto que su interés no se aloja principalmente allí sino en la posibilidad que la ficción nos ofrece para acercarnos a esas experiencias.

El eje del libro es la experiencia individual de haber sido hijo/a de desaparecidos/as, aunque desde este núcleo el texto irradia hacia la experiencia colectiva, experimentada a través del paso por la agrupación H.I.J.O.S. (Hijos por la Identidad y la Justicia contra el Olvido y el Silencio) creada en 1995. El foco del libro se abre luego de un modo algo inquietante, puesto que se incluyen en uno de los capítulos las voces de los hijos de los represores. Lo que anuda el corpus es entonces la experiencia de ser segunda generación del drama político que atravesó nuestra sociedad. 
En el primer capítulo, el más conceptual del libro, la autora inscribe parte del corpus en línea con lo sucedido a partir de otras experiencias de violencia radical. Así, en diálogo con los trabajos de Jorge Semprún y Primo Levi se reconoce algo específico en sus obras y en las de los HIJOS/AS: la experiencia límite hace nacer al escritor. Ligado a esto, las voces de los HIJOS/AS que quieren ser leídos como escritores/as y no como HIJOS/AS. Esto abre una inquietud para los lectores: ¿leemos a los HIJOS como si leyéramos a cualquier escritor? ¿Nos vinculamos con esas ficciones como si no tuvieran por detrás la experiencia vivida? ¿Cómo leemos cuando el vínculo entre experiencia y ficción está teñido de la situación límite? ¿Cómo articulamos todo esto con la categoría paradojal y algo resbaladiza de "víctimas"?

$\mathrm{Si}$, por un lado, la mirada precisa de Basile le permite ver los matices de la experiencia de los HIJOS/AS, por el otro, la toma de distancia analítica la habilita a mostrar la totalidad. A través de esto la autora se concentra en tres dimensiones que recorren estas narraciones y que atraviesan la construcción de sus memorias. Se trata, en primer lugar, de una narrativa humanitaria, heredera de las luchas de las organizaciones de derechos humanos que surgieron al calor del terrorismo de estado. Un modo de denunciar concentrado en el carácter humano de las víctimas y en el rasgo defensivo de sus prácticas orientadas a frenar el accionar estatal. En segundo lugar, una narrativa de corte militante que propone no recordar a sus padres sólo como víctimas, portadores de un derecho humano a defender, sino también como protagonistas activos de sus vidas y de la historia. En ese sentido, los hijos recuperan las prácticas políticas de sus padres, lo que implicó una repolitización de sus figuras. Una tercera narrativa es la familiar, aquella mediante la cual los hijos buscan trazar un perfil de sus padres no sólo desde su condición de víctima y/o su experiencia política sino desde el armado del rompecabezas de la cotidianidad que les devuelve a sus hijos una mirada de los desaparecidos en tanto padres, pero también en tanto hijos, o compañeros de trabajo, es decir, sujetos insertos en una red de relaciones afectivas. La tensión entre lo afectivo y lo político es lo que finalmente ofrece la amalgama con la que los HIJOS le dan forma a la voluntad de comunidad.

En términos de su escritura, los HIJOS al comienzo inscriben sus narraciones en clave testimonial. Luego, en cambio, mediante la ficción reponen "lo real" al identificar narrador y autor, para luego tensar esa relación con la ironía, la burla, lo onírico y lo fantástico, como si retomaran la senda imposible de narrar aquello que ha sido imposible de ser vivido. En esta segunda etapa de la escritura de los HIJOS se puede advertir una distancia crítica que en ocasiones alcanza la incorrección política. De allí el valor del corpus elegido, es el lugar de enunciación de los HIJOS lo que habilita que se tensen las cuerdas de lo establecido sin quedar posicionadas en un lugar pasible de ser juzgado moralmente.

En cada uno de los capítulos siguientes la autora ofrece un recorte en torno a alguna dimensión puntual de esta heterogénea experiencia. En el segundo capítulo aborda la experiencia de "los niños educados", a partir de dos documentales (El edificio de los chilenos, dirigido por Macarena Aguiló y Susana Foxley y La guardería, realizado por Virginia Croatto) y un libro (La guardería montonera: la vida en Cuba de los hijos de la Contraofensiva, de Analía Argento). Las tres obras narran la experiencia de los hijos de militantes políticos de Chile y Argentina que dejan sus hijos e hijas en Cuba para volver a sus países a enfrentar los gobiernos dictatoriales. Esa decisión se aloja en el marco de un proyecto pedagógico de más largo alcance: la construcción del niño nuevo, en sintonía con el hombre nuevo planteado por Ernesto Guevara. La autora aborda cómo se construye una mirada sobre los niños y su educación en estas obras, cuánto se tensionan los roles clásicos de padres, hijos, y la familia en general; cuáles son los deberes y derechos que les asignan a los niños y niñas. Ambos casos muestran una mirada crítica de aquella experiencia (la soledad, la adultización de la niñez, la sobrecarga de mandatos políticos), sin dejar de incluir algunos de sus aspectos positivos (el compañerismo con otros niños). Se diferencian en que en el caso chileno la mirada se asocia con la derrota política de esa generación y en el caso argentino la derrota de la contraofensiva es resignificada en clave de continuidad política, a partir de la llegada al poder del kirchnerismo.

El capítulo siguiente, Infancia clandestina: un mundo escindido, aborda el libro Kamchatka, de Marcelo Figueras, y el film homónimo de Marcelo Piñeyro, la película Infancia clandestina de Benjamín Ávila, y 
los libros La casa de los conejos, de Laura Alcoba, Una muchacha muy bella de Julián López y Pequeños combatientes de Raquel Robles. A través de este corpus la autora indaga la experiencia de los niños que vivieron sus infancias con un doble régimen, por un lado el mundo "normal" de cualquier niño y por el otro uno "secreto" derivado de la clandestinidad que atravesaban sus padres. ¿Cómo se vinculaban estos niños con sus padres que a su vez eran militantes? ¿Cómo se articulaba el rol paterno y materno de cuidar de sus hijos y al mismo tiempo exponerlos a ese mundo secreto y riesgoso de la clandestinidad? ¿En qué medida esos padres tienen la posibilidad de ser vistos como buenos padres y a la vez como buenos militantes por sus hijos? La clandestinidad tensiona estas figuras y los avatares atravesados por los niños son prueba de ello. En este capítulo se ve con notable claridad cómo las obras articulan y tensionan los tres modos de pensar a sus padres señalados anteriormente: como víctimas, como militantes y como padres.

El capítulo cuarto, Infancias huérfanas, se concentra en la obra del escritor Féliz Bruzzone, por un lado en los relatos de su libro 76, y por el otro en su novela Los topos. Bruzzone trabaja a partir de la comicidad y la provocación, y logra que sus textos sean escandalosos y al mismo tiempo livianos y divertidos. En su obra la orfandad suspendida (porque el status de sus padres es el de la desaparición) deviene un proceso de extrema ruptura: la familia rota, la casa rota, la identidad rota y la ficción paranoica. En estos textos se puede ver el costado más políticamente incorrecto de la literatura producida por los HIJOS. Hay una tensión permanente por dialogar de modo crítico, incluso mordaz, con las formas en que los HIJOS han emergido a la esfera pública, en especial a través de la agrupación H.I.J.O.S.. Las textualidades que logra Bruzzone son temblorosas y precarias, personajes sin certezas ni convicciones, perdidos y dubitativos, que realizan acciones cruzadas en extremo por el azar, en suma: un mundo casi inverso al construido por las organizaciones de derechos humanos, muchas de las cuales construyen sus certezas anudadas al poder del lazo biológico (lazo que Bruzzone porta y que relee en una clave diferente).

En el capítulo quinto, Infancias apropiadas, se abordan las experiencias de aquellos hijos de desaparecidos que fueron criados lejos de sus familias de origen. Este capítulo es más histórico-descriptivo que literario y aborda dos momentos, la apropiación (que debe ser diferenciada de la adopción) y la restitución. Lo realiza a través de las múltiples dimensiones que acompañan estos procesos: jurídica, psicoanalítica, identitaria y familiar. El corpus elegido incluye el libro Botín de guerra de Julio Nosiglia y el film del mismo nombre de David Blaustein; los libros Reencuentro, crónica de la restitución de una identidad, de Alfredo Hoffman, De vuelta a casa. Historia de nietos restituidos, de Analía Argento y el film La parte del todo, dirigido por Andrés Martinez Cantó, Santiago Nacif Cabrera y Roberto Persano. Aquí nuevamente prima la diversidad de experiencias, tanto en los tratos recibidos por sus familias apropiadoras (o en algunos casos adoptantes), como en la respuesta ofrecida luego de conocido su verdadero origen. Por otro lado, hay relatos en los que el conflicto emerge de manera más cruda y conforman lo que Basile llama las contranarrativas. Los casos de Mariana Eva Pérez y Victoria Donda (cuyos hermanos/as rechazan a sus familias biológicas) muestran la cara más dura del proceso de restitución.

El anteúltimo capítulo llamado Infancias violentas tensiona el corpus porque, como decía, incluye las voces de los hijos de los represores, que cuestionan las figuras de sus padres. La decisión de Basile es audaz y analíticamente sólida; además, la inclusión de estas voces se vuelve social y políticamente indispensable, en la medida en que estrecha lazos con el mundo de los victimarios, pero no lo hace como a veces se exige a partir de la idea vacua de la reconciliación sino a partir del reconocimiento de que estos hijos, ya adultos y adultas (son en su mayoría mujeres) fueron y son también victimas de sus padres. El capítulo incluye además un análisis de cómo otras voces de hijos de militares fueron reconstruidas por la ficción. Para eso indaga en Papá de Federico Jeanmaire, Una misma noche de Lepoldo Brizuela y Soy un bravo piloto de la nueva China de Ernesto Semán.

El libro cierra con un capítulo titulado Pasado en presente en el que el foco vuelve sobre los HIJOS y la pregunta en torno de cuál ha sido su aporte para pensar los desaparecidos. Se destaca en ese recorrido la capacidad de los hijos de recuperar la dimensión particularizada y cotidiana de sus padres, un poco a contramano de la generalización algo homogeneizante de la referencia a los “30000”, y también su aporte a 
Santiago Cueto Rúa. Basile, Teresa (2019). Infancias. La narrativa argentina de HiJOS. Villa María...

repolitizar esas figuras, a partir de tensar algunos acuerdos básicos de la narrativa humanitaria. Ese modo de revisitar las figuras de sus padres también fue habilitado, cierra Basile, por gobiernos como los kirchneristas que anclaron muchos de sus discursos y sus prácticas en el marco de lo que se conoce como la generación diezmada, es decir, la de los padres de estos HIJOS/AS.

CC BY-NC-SA 